\title{
Modelling the adaptive value of intertidal migration and nursery use in the bivalve Macoma balthica
}

\author{
J. G. Hiddink $k^{1,2, *}$ \\ ${ }^{1}$ University of Groningen, Department of Marine Biology, PO Box 14, 9750 AA Haren, The Netherlands \\ ${ }^{2}$ Present address: School of Ocean Sciences, University of Wales, Bangor, Menai Bridge, Anglesey LL59 5AB, United Kingdom
}

\begin{abstract}
Ontogenetic niche changes (migrations) are worthwhile when spatial differences that are age or size selective exist. In the Wadden Sea, a Macoma balthica individual migrates twice; from the primary settlement locations at the low tidal flats to the high level nursery (spring migration) and back to the low intertidal at an age of 9 mo (winter migration). Benefits of migration may be found in differences in predation pressure between the low and high tidal flats. This study evaluates, by means of a model based on empirical data, under what conditions the costs of migration (increased mortality) are traded-off against an increased reproductive output (RO) due to avoiding size-selective predation (by shrimps, crabs, polychaetes and birds) and size-selective infection by the parasitic trematode Parvatrema affinis. Density was modelled as a function of predation and migration mortality. The RO was compared for $M$. balthica that did and did not migrate, and for different times of the spring and winter migration. RO was maximised for $M$. balthica that settle in the high intertidal and migrate to low tidal flats at an age of approximately 9 mo. Shrimp predation makes living on the low tidal flats unfavourable for small $M$. balthica. Parasitation by $P$. affinis makes it beneficial for $M$. balthica to leave the high tidal flats around the age of $1 \mathrm{yr}$. In conclusion, migrations of $M$. balthica to and from nurseries on high tidal flats of the Wadden Sea may be seen as an adaptation to avoid shrimp predation on the juveniles and parasite infection of the adults. Although the costs of migration are large, fitness is increased due to the migration because it is traded off by an increased RO.
\end{abstract}

KEY WORDS: Migration $\cdot$ Predation $\cdot$ Parasites $\cdot$ Mortality $\cdot$ Wadden Sea

\section{INTRODUCTION}

Nurseries, where juveniles are abundant and adults are scarce, are found throughout the animal kingdom. Very clear examples of differential habitat use can be found in many metamorphosing animals, such as insects and amphibians with an aquatic larval stage. Many examples are also found in the marine environment. Juvenile plaice Pleuronectes platessa live on tidal flats and in other shallow coastal areas, while adults live in deeper waters (Wennhage \& Pihl 2001). Juvenile shore crabs Carcinus maenas live concentrated in the highest intertidal, whilst adults are most abundant in the low intertidal and subtidal (Klein Breteler 1976). As nurseries are spatially separated from the locations where the adults live, migrations are an inevitable consequence of nursery use.
Change of living area by migration will be adaptive when the benefits of the migration (the difference in survival or energy balance between 2 areas) are larger than the costs of the migration (energetic costs or number of animals dying due to the migration). Therefore, the animals have to trade off the short-term costs of migration against the possible long-term benefits in terms of increased reproductive output (RO), if the costs of migration are constant. The moment in the life cycle that is optimal to change habitat, is the moment when growth or survival in the first habitat becomes lower than in the second habitat (Werner \& Gilliam 1984).

This study examines the adaptive value of migrations and nursery use for the bivalve Macoma balthica (L.). M. balthica is a small bivalve found in coastal areas in temperate and arctic regions of the Northern Hemisphere (Beukema \& Meehan 1985). In the Wad- 
den Sea, the 0-group (juveniles) of this species are mainly found on the high intertidal flats. Older animals (1+ group, which will be called adults in this paper) are more widespread, and are found in both the low and high intertidal and the subtidal zones of the Wadden Sea and the adjacent North Sea (Beukema 1993).

Since the locations where adults and juveniles live are partly spatially separated, Macoma balthica undertakes migrations between these locations. Juvenile $M$. balthica settle in May at a size of $300 \mu \mathrm{m}$ in the low intertidal. Subsequently, they all migrate in the direction of the high tidal flats (compare April and August distribution of 0 -group in Fig. 3 in Hiddink et al. 2002c); $50 \%$ of these animals end up in the high intertidal as defined in this study $(0.25 \mathrm{~m}$ above mean tide level, MTL). Hiddink \& Wolff (2002) sampled 57 stations on a tidal flat 21 times over the course of 2 yr to quantify migration flows during both spring and winter migration. Mortality is 1.5 to 2 times higher during migration periods (Hiddink \& Wolff 2002), possibly due to fish predation on byssus drifting $M$. balthica (Hiddink et al. 2002a). Due to the additional mortality caused by the migration, the number of migrating animals is larger than the number relocating. During the spring migration, $55 \%$ of the animals migrated (the number that relocated from low to high plus the number disappearing and probably dying due to the risks of the migration) between May and July. The other $45 \%$ stayed where they were before the spring migration until December. Between December and February, juvenile $M$. balthica ( $5 \mathrm{~mm}$ ) migrate back to the low intertidal and the North Sea (Beukema \& De Vlas 1989, Hiddink \& Wolff 2002). During the winter migration, $73 \%$ of the population migrated (Hiddink \& Wolff 2002).

Migration occurs via byssus drifting, where increased drag on byssus threads decreases sinking rates (Sigurdsson et al. 1976, Sörlin 1988). Sinking rates depend on shell size and thread length and can be up to 5 times lower for small bivalves with a byssus thread compared to small bivalves without (Sörlin 1988, Beukema \& De Vlas 1989). The distances that are covered during migration periods are large (up to $25 \mathrm{~km}$; Beukema \& De Vlas 1989) and it is therefore unlikely that these distances are covered by crawling animals.

A factor may stimulate nursery use if it: (1) acts in a size or age selective way; and (2) is not homogeneously distributed over the low and high tidal flats. Site and size selective predation on Macoma balthica was found for many groups of predators. Stomach content analysis and size selection experiments in the laboratory showed that epibenthic predators, like the shrimp Crangon crangon, the crab Carcinus maenas and flatfish, only eat small $M$. balthica and are more abundant in the low intertidal (Hiddink et al. 2002b). Exclosure studies also showed that exclosure of epibenthic predators had a large effect on small $M$. balthica in the low intertidal zone, but not in the high intertidal zone nor on larger M. balthica (Hiddink et al. 2002b). Therefore, the higher abundance of juvenile $M$. balthica in the high intertidal zone after migration, is relatively increased due to the higher predation on juvenile $M$. balthica in the low intertidal zone. Caging studies and stomach content analysis showed that the polychaetes Arenicola marina and Nereis diversicolor can eat large numbers of $M$. balthica <1 mm (Hiddink et al. 2002c). Waders generally select for $M$. balthica $>10 \mathrm{~mm}$ (Hulcher 1982). Further, the parasite Parvatrema affinis only infects $M$. balthica $>9 \mathrm{~mm}$ in the high intertidal zone (Hulscher 1973, Swennen \& Ching 1974, Lim \& Green 1991, Edelaar et al. 2002). This trematode is restricted to $M$. balthica, and uses it both as primary and secondary host (Swennen \& Ching 1974, Lauckner 1983). Its final hosts are ducks, waders and gulls that feed on M. balthica (Lauckner 1983).

Beukema (1993) proposed the hypotheses that the nursery use of Macoma balthica, with a spring and winter migration, was an adaptation: (1) to avoid epibenthic predation on juveniles; (2) to avoid disturbance of the juveniles; (3) to avoid parasitation and bird predation on the adults; and (4) to find the best growing conditions for both adults and juveniles. Individual migrants should trade-off a high probability of increased survival and growth in the long term (because the migration may enable using predation and parasitation refuges, which may be different for 0-group and older animals), against the risk of reduced survival in the short term (because of the losses caused by the migration).

The aim of this study is to test the general hypothesis that nursery use of Macoma balthica is adaptive. For each of the hypotheses proposed by Beukema (1993; see above), I examined whether nursery use of $M$. balthica increases fitness. Moreover, I assessed whether the observed timing of the migration to and from the nurseries maximises fitness. These hypotheses were tested by construction of a model that calculates fitness for $M$. balthica for different migration strategies (whether or not to migrate and the timing of migrations) as a function of migration risk, predation pressure by different predators and the parasite infection rate. Finally, the model was used to examine if $M$. balthica can improve survival by timely migrations between low and high tidal flats.

\section{METHODS}

Model construction strategy and general model structure. The expected lifetime reproductive output (RO) of an individual organism is given by multiplica- 
tion of a survival term until adulthood times the per capita RO of animals reaching adulthood times the survival term of the adult animal. This can be described by:

$$
\mathrm{RO}=s_{\mathrm{j}, \mathrm{i}} \cdot m_{\mathrm{i}, \mathrm{j}} \cdot s_{\mathrm{a}, \mathrm{j}} \cdot \mathrm{PCRO}_{\mathrm{j}}
$$

where the first subscript of the survival probability, $S$, refers to the life stage ( $\mathrm{j}$ : juveniles; $\mathrm{a}$ : adult) and the second subscript refers to the environment (i: low tidal flat; $j$ : high tidal flat); $m_{i, j}$ is the survival probability of the migration from environment $i$ to $j_{i} \mathrm{PCRO}_{j}$ is the per capita RO in environment $\mathrm{j}$. It is assumed that only juvenile animals can migrate.

A migration from Environment 1 to 2 (after primary settlement in Environment 1) upon maturing will be worthwhile if $m_{1,2} \cdot s_{\mathrm{a}, 2} \cdot \mathrm{PCRO}_{2}>s_{\mathrm{a}, 1} \cdot \mathrm{PCRO}_{1}$, otherwise staying will be the optimal strategy. In this study, it was assumed that $\mathrm{PCRO}_{1}=\mathrm{PCRO}_{2}$ and that migration mortality does not depend on the time of migration. Therefore, whether a migration is worthwhile depends on survival in the 2 environments and the magnitude of the migration mortality.

The survival in an environment $\left(s_{\mathrm{i}, \mathrm{j}}\right)$ depends on the number of predators, the number of prey, the functional response of the predator, the size of the prey and the size selection of the predators. The number of predators and the size of Macoma balthica change throughout the year.

This study examines the interaction of Macoma balthica growth with predator consumption rates at the low and high tidal flats and therefore, an evaluation of the above-described inequality is complicated. For this purpose, an age-structured model was constructed that calculates the density of a $M$. balthica year class, per $1 \mathrm{~mm}$ length-category, from Age-0 (April of their first year) for a period of $5 \mathrm{yr}$. M. balthica grow from one length class to the next and density is a function of mortality by predation and migrations only. All $M$. balthica live either on the low or on the high tidal flats during a time step $(1 \mathrm{mo})$. They can migrate to the other location in the next month.

All parameter values, predator densities and Macoma balthica settling density were derived empirically from field and laboratory studies (Hiddink \& Wolff 2002, Hiddink et al. 2002a, b,c). Field studies were carried out at the tidal flats of the Groninger Wad in the Dutch Wadden Sea from 1998 to 2001, and data from all 4 years were used to construct the model. The model was partitioned in low (below $0.25 \mathrm{~m}$ 'Nieuw Amsterdams Peil', NAP, Dutch ordinance level, close to mean tidal level) and high (above $0.25 \mathrm{~m}$ NAP) tidal flats, which had different predator densities and predation rates. For factors that were not studied on the Groninger Wad (e.g. parasite infection rates and oystercatcher feeding biology), literature values were used from tidal flat areas as close as possible and always in the Wadden Sea (see elsewhere in 'Methods' for the literature sources used).
Fitness measure. Fitness was defined as the total RO of the population during $5 \mathrm{yr}$. In the model, every Macoma balthica shows the same behaviour and therefore, the RO is likewise an individual fitness measure. $M$. balthica generally starts reproducing at Age2 (Beukema et al. 2001). Few M. balthica reach an age of more than $5 \mathrm{yr}$ in the field (Van der Meer et al. 2001) and for practical reasons, RO was calculated only for these $5 \mathrm{yr}$. RO was calculated from the number of $M$. balthica uninfected by the trematode parasite Parvatrema affinis, alive in March for the 4 reproductive years; as fecundity correlates linearly with age and biomass (Beukema et al. 2001), this number was multiplied by the age of the $M$. balthica.

Description of the model. Growth: Length data from the field were used to fit growth rates for the model. As these lengths are changed by size-selective predation, this probably leads to an overestimation of growth rates for small Macoma balthica and therefore, to an underestimation of predation rates. Unfortunately, not enough growth data for $M$. balthica in the absence of size-selecting predators (exclosure studies) were available to fit a growth curve that is unbiased by size selection. Nevertheless, Hiddink et al. (2002b) found no significant differences between treatments with and without epibenthic predators in the length of 0 -group and $1+$ group $M$. balthica over 2 to 3 mo experiments. Growth rates on the low and high tidal flats were assumed to be equal for the same reason and because no substantial differences in length growth were found between low and high tidal flats on the Groninger Wad.

In the model, Macoma balthica grew from size class to size class according to a seasonalised Von Bertalanffy growth curve with $K=0.75$ and $L_{\infty}=17.5 \mathrm{~mm}$, both derived from a Ford-Walford-plot (King 1995) of length data from the Groninger Wad. Monthly growth rates were adjusted by a constant (which can be interpreted as the result of food availability and temperature, and followed a seasonal cycle with maximum growth rates in April and May and no growth in December and January), to generate the observed seasonal growth; 0-group $M$. balthica grow from April to October, while 1+ group animals show high growth rates from April to July. This factor was adjusted per month to fit the Von Bertalanffy growth curve that was generated by the model, to lengths of the 1998 year class on the Groninger Wad.

Preliminary tests of the model showed that size selection by high densities of epibenthic predators could increase mean shell length of the population by maximally $1 \mathrm{~mm}$ at a length of $14 \mathrm{~mm}$. This deviation is smaller than between-year differences in the field (Van der Meer et al. 2001). In the model, Macoma balthica settled in April at Age- 0 in the $0.5 \mathrm{~mm}$ length class at a density of $10000 \mathrm{~m}^{-2}$ (Hiddink \& Wolff 2002). 
Predation: Predators considered in this study were the brown shrimp Crangon crangon L., 0-group and older (1+ group) shore crabs Carcinus maenas (L.), the ragworm Nereis diversicolor (Müller), the lugworm Arenicola marina (L.) and the oystercatcher Haematopus ostralegus L.

Predator densities: Densities of shrimps, crabs and polychaetes were determined on the tidal flats of the Groninger Wad between 1998 and 2001 (Hiddink et al. $2002 b, c)$. All densities were calculated separately for the low and high tidal flats (Fig. 1). Average densities per month were used, with missing data being linearly interpolated. In the model, equal predator densities were used for each of the 5 yr examined.

Densities of oystercatchers Haematopus ostralegus foraging on the tidal flats were calculated from high tide counts by De Jong \& Koks (1999), a method justified by Yates \& Goss-Custard (1991). H. ostralegus roosting at the saltmarsh at high tide were assumed to forage in an area of $20 \mathrm{~km}^{2}$ at low tide, which includes $7 \mathrm{~km}^{2}$ of my study area. Spatial distribution of waders is primarily governed by food abundance in the high intertidal, but is limited by emersion time in the low intertidal (Wolff et al. 1975). For reasons of simplicity, the predation pressure on Macoma balthica by $H$. ostralegus on the low and high tidal flats was assumed to be proportional to the exposure time (ratio low to high $=3.1: 9.8 \mathrm{~h}$ per tidal cycle).

Functional response: The relation between the density of Macoma balthica in the suitable size range and predator consumption was described by a functional response (FR) that was fitted with a regression through empirical data. Whenever possible, separate FRs were fitted for low and high tidal flat predators. The FRs fitted had a Holling Type I $(y=a x)$, Holling Type II $(y=a x /[1+b x])$ or Holling Type III $(y=a /[1+$ $\exp \{-b(x-c)\}])$ shape, where $y$ is predator consumption (prey per predator per month), $x=M$. balthica density $\left(\mathrm{n} \mathrm{m}^{-2}\right)$ and $a, b$ and $c$ are parameters (Holling 1965). The Holling-type curve that showed the best fit with empirical data was selected for the final FR.

The deposit-feeding polychaetes probably feed on Macoma balthica spat in numbers proportional to the amount of sediment they process. Therefore, and because field observations showed considerable scatter, a linear relation (Type I) between $M$. balthica density and intake rate was assumed (Fig. 1). The parameter value a (\# $M$. balthica eaten worm ${ }^{-1} \mathrm{mo}^{-1} \mathrm{M}$. balthica ${ }^{-1}$ $\mathrm{m}^{-2}$ ) was calculated from the average number of $M$. balthica per examined stomach of Nereis diversicolor and Arenicola marina and the gut through-put time (Hiddink et al. 2002c). M. balthica consumption as a function of density was never measured for Haematopus ostralegus. From available data on intake rates and densities of M. balthica (Hulscher 1982, Buns- koeke et al. 1996, B. J. Ens pers. comm.), a Type II FR curve was constructed. The effect of temperature on predation rates of predators was ignored, because knowledge on the relation between temperature and predation rates is scarce for most predators. Furthermore, the short yearly predation period of most predators on $M$. balthica would result in only minor effects of temperature on predation rates.

Size selection: For each predator species, a size selection factor between 0 and 1 was assigned per Macoma balthica length category, based on laboratory size-selection experiments (Hiddink et al. 2002b), stomach content analysis (Hiddink et al. 2002b,c) and on literature values for Haematopus ostralegus (Hulscher 1982). The maximum selection value was set at 1 ; a 0 -selection value indicates that the size class was rejected, a 1 indicates strong preference for this size class.

Calculation of consumption: The number of consumed Macoma balthica per predator and per time step (1 mo) was calculated from the overlap of the size distribution of the $M$. balthica population and the sizeselection factors, M. balthica density and the FR. First, densities per size class were multiplied with the selection factors to calculate a total density that is corrected for the size selection: the density perceived by the predator. From this density, the number of consumed $M$. balthica was calculated from the FR. This number was partitioned over the different $M$. balthica size classes according to the density $\times$ size-selection ratios.

Parasite infestation: On tidal flats in the Dutch Wadden Sea, Parvatrema affinis only occurs in the high intertidal and only in Macoma balthica larger than $9 \mathrm{~mm}$. More than $30 \%$ of the large $M$. balthica on high tidal flats may be infected (Hulscher 1973, Swennen \& Ching 1974). Because infection increase rates per month were needed for the calculations, lengths were recalculated to ages, using the Von Bertalanffy growth curve. The slope of the parasite incidence against age (in months) was used as the monthly parasite increase rate $(1.03 \%$, $\mathrm{R}^{2}=0.76$ ), for $M$. balthica above $9 \mathrm{~mm}$ (the intersection with the $x$-axis) on the high tidal flats. In the model, infected bivalves cannot lose their infection and suffer no additional mortality; however, they can be eaten by predators. As $M$. balthica cannot reproduce due to parasitic castration (Lauckner 1983, Pekkarinen 1987), the animals are dead from a fitness point of view.

Migration mortality. Migrations are dangerous for Macoma balthica because predation during pelagic drifting is higher than when staying buried (Hiddink et al. 2002a). From a field study, the additional mortality due to the spring and winter migrations was estimated at 13 and $24 \%$, respectively; assuming that the whole population drifted and that only a fraction of the animals really relocated (Hiddink \& Wolff 2002). In the model 

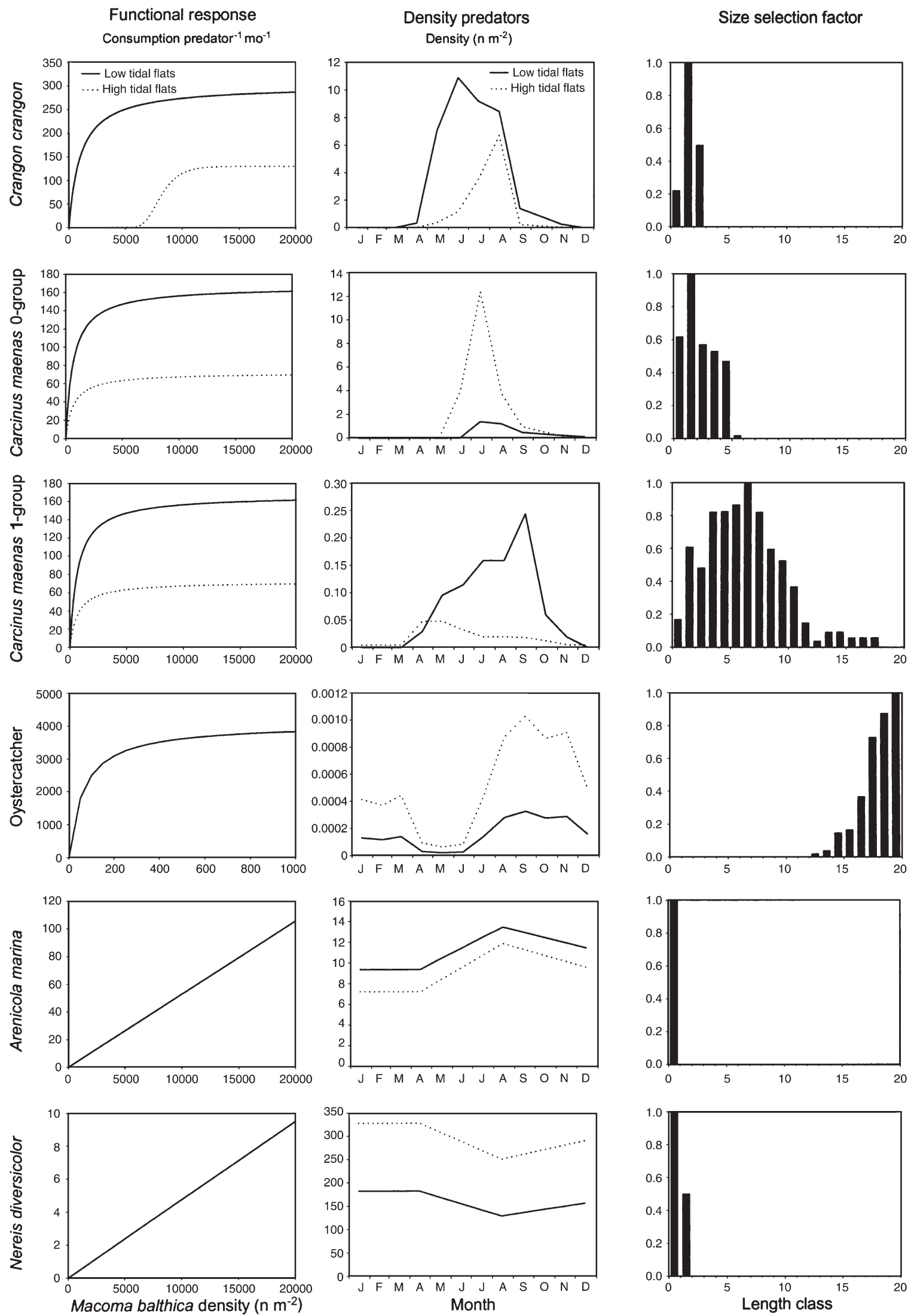

Fig. 1. Functional responses (FRs), density and size selection of all predators. Note the different $x$-axis scaling for the Haematopus ostralegus FR. For Crangon crangon and Carcinus maenas 0 and 1+ groups, a different FR was used for the low and high tidal flats 
calculations for each migration at any time of the year, from low to high tidal flats, the $M$. balthica suffer the additional spring migration mortality, while for migrations from high to low, they suffer the additional winter migration mortality.

As the energetic costs of forming a byssus thread are very small (Hiddink et al. 2002a), these costs were not incorporated in this study. Although Macoma balthica probably cannot forage during migrations, possibly leading to depletion of energy reserves, this process was not considered important.

\section{RESULTS}

\section{Input}

The data used as input for the model are summarised in Fig. 1 and Table 1. Some of the FR curves showed a rather poor fit with the field data, especially those for the polychaetes and crabs. Predation rates of Crangon crangon and Carcinus maenas on the low tidal flats were higher than those at the high flats at equal Macoma balthica density because individuals were bigger and immersion times were longer (Fig. 1). For 1+C. maenas; no data to fit a FR were available, therefore the 0-group FR was also used for the 1+ group.

\section{Fit of the model to empirical data}

The model underestimated the mortality in the field by a factor of 2 (Fig. 2). Especially in the period September to January at Age-0, the model predicted a constant population size (no mortality), while mortality in the field was high. Clearly, some factors causing mortality were not included in the model. Since mortality of Macoma balthica at the Groninger Wad could not completely be explained, the model is only useful for testing hypotheses for factors that have been included in the model.



Fig. 2. Macoma balthica. Density over time $( \pm 95 \%$ confidence interval $)$ for the 1998 and 1999 year classes at the Groninger Wad as calculated by the model

\section{Fitness as a function of migration date in the model}

Survival from month to month

From the model, the survival from one month to the next (Fig. 3) was calculated. Below Age-1, survival of Macoma balthica is much lower than above Age-1. Survival is highest in the high intertidal before Age-1 and is higher in the low intertidal after Age-1.

Fitness as a function of migration date for the 'winter' migration from high to low tidal flats

In Fig. $4_{\nabla}$ the cost of migration is incorporated in calculations of reproductive output for different moments of migration from the high to the low tidal flats ('winter' migration), assuming primary settlement on the high intertidal. The time for migration that results in the highest RO lies before Age-1, at an age of about 9 mo.

Table 1. Shape (Holling Type I, II or III), parameter values and fit of the regression of the functional responses for all predators. The functional response (FR) describes the relation between Macoma balthica density ( $\mathrm{n} \mathrm{m}^{-2}$ ) and number of M. balthica consumed per predator per month

\begin{tabular}{|lcccccc|}
\hline Species & Tidal level & FR type & $\mathrm{R}^{2}$ & $\mathrm{n}$ & $a$ & $b$ \\
\hline Crangon crangon & Low & II & 0.65 & 8 & 0.301 & 0.001 \\
Crangon crangon & High & III & 0.72 & 4 & 130 & 0.002 \\
Carcinus maenas 0 and 1+ groups & Low & II & 0.28 & 4 & 0.250 & 0.0015 \\
Carcinus maenas 0 and 1+ groups & High & II & 0.08 & 6 & 0.108 & 0.0015 \\
Haematopus ostralegus & Both & II & 0.37 & 24 & 650 & 0.016 \\
Arenicola marina & Both & I & 0.01 & 8 & 0.00526 & \\
Nereis diversicolor & Both & I & 0.21 & 7 & 0.00047 & \\
\hline
\end{tabular}




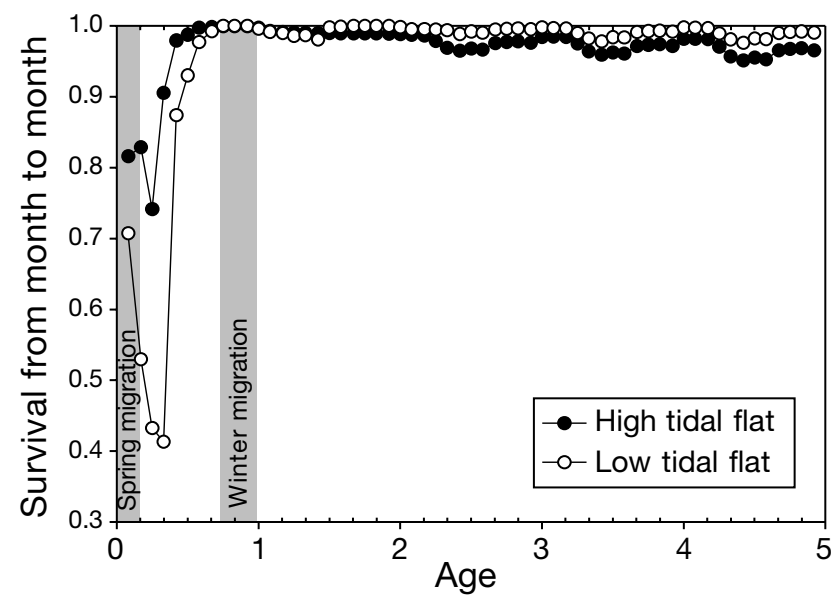

Fig. 3. Macoma balthica. Survival (ratio next month to current month, minus parasite-infected $M$. balthica) at low and high tidal flats from the model calculations, without migration

This coincides with the moment at which the winter migration was observed in the field.

All factors included in the model were varied between 0 (species or process not present in model) and $200 \%$ of the observed value. If the shape of the curve that describes the RO as a function of migration date-

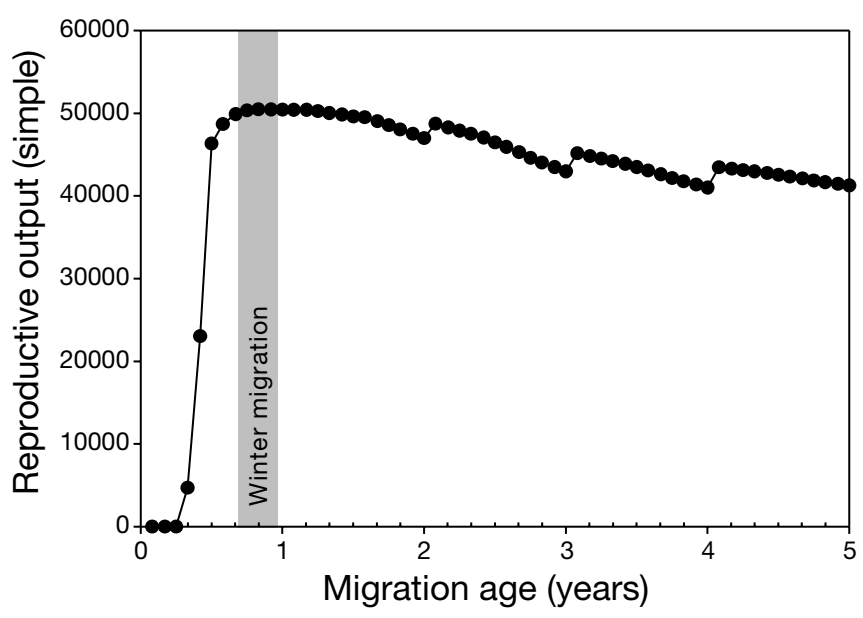

Fig. 4. Macoma balthica. Reproductive output of a population, calculated by the model, for $M$. balthica migrating from the high to the low tidal flats ('winter' migration) at different ages. The first and last point on the time axis represent 'always low' and 'always high' and therefore, no migration. From the model, the highest reproductive output is found for migration from the high to the low tidal flats that lies around Age-1 (which is also the age at which the winter migration was observed). The saw teeth in the curve are caused by the mortality caused by the migration (see Fig. 5G). As in the model, $76 \%$ of the population survives the winter migration; in the short term, the population size is reduced by $24 \%$ by the migration. Therefore, when migrating before the evaluation moments (March, reproduction), the population size is reduced as compared with migration directly after reproduction changes upon altering the input factor, this factor affects the migration moment that results in the highest RO. If, however, only the level and not the shape of the curve changes, the factor does affect the final RO, but not the optimal moment to migrate.

Only the abundance of shrimps, migration risk, growth rate and parasite infection rates affected the shape of the curves to an extent that the best moment to migrate changed (Fig. 5). If there are no shrimps (0\%), the highest RO is reached when Macoma balthica immediately migrates to the low intertidal after settlement, while when there are many shrimps (>25\% of observed density), a migration to the low intertidal within the first $5 \mathrm{mo}$ would decrease the RO (Fig. 5D). If there were no parasites, leaving the high tidal flats would decrease RO, but if parasite infection rates become above $80 \%$ of the calculated field value, a migration from the high to the low tidal flats after reaching Age-1 increases RO (Fig. 5I). If the migration risk is too high (less than $70 \%$ survival during migration), the migration does not increase the RO of the population. If migration survival is higher, the optimal moment to migrate will be determined by shrimps and parasites around Age-1 (Fig. 5G). Finally, in populations with a $L_{\infty}$ smaller than $14 \mathrm{~mm}$, migrations will not optimise the RO (Fig. 5H). Other predators like Nereis diversicolor and Carcinus maenas 0-group have a large effect on the RO, but not on migration moment giving the highest RO (Fig. 5B,E). Arenicola marina, 1+ group $C$. maenas and Haematopus ostralegus have only a small effect on the RO (Fig. 5A,C,F).

Starting density (= density at settlement) has an effect on the RO at different migration dates (Fig. 5J). At very high settlement densities (>59000 $\mathrm{m}^{-2}$ ), the RO output will be highest when Macoma balthica does not migrate after primary settlement in the low intertidal (migration from high to low at Age-0); at lower densities, the RO is maximal when migrating around the age of $1 \mathrm{yr}$.

Fitness as a function of migration date for the 'spring' migration from low to high tidal flats

The optimal moment of migration from low to high tidal flats was only affected by shrimp abundance (Fig. 6). Normal and high shrimp abundances make it necessary to leave the low intertidal as soon as possible. At low shrimp abundances, the best strategy is to always stay in the low intertidal (migration from low to high as late as possible). At normal shrimp abundances, predation by shrimps in the low intertidal is so strong that the Macoma balthica population almost dies out when it stays in the low intertidal. Therefore, parasite infection rates, migration mortality and all other factors did not affect the fact that leaving the low intertidal as soon as possible maximises RO. 

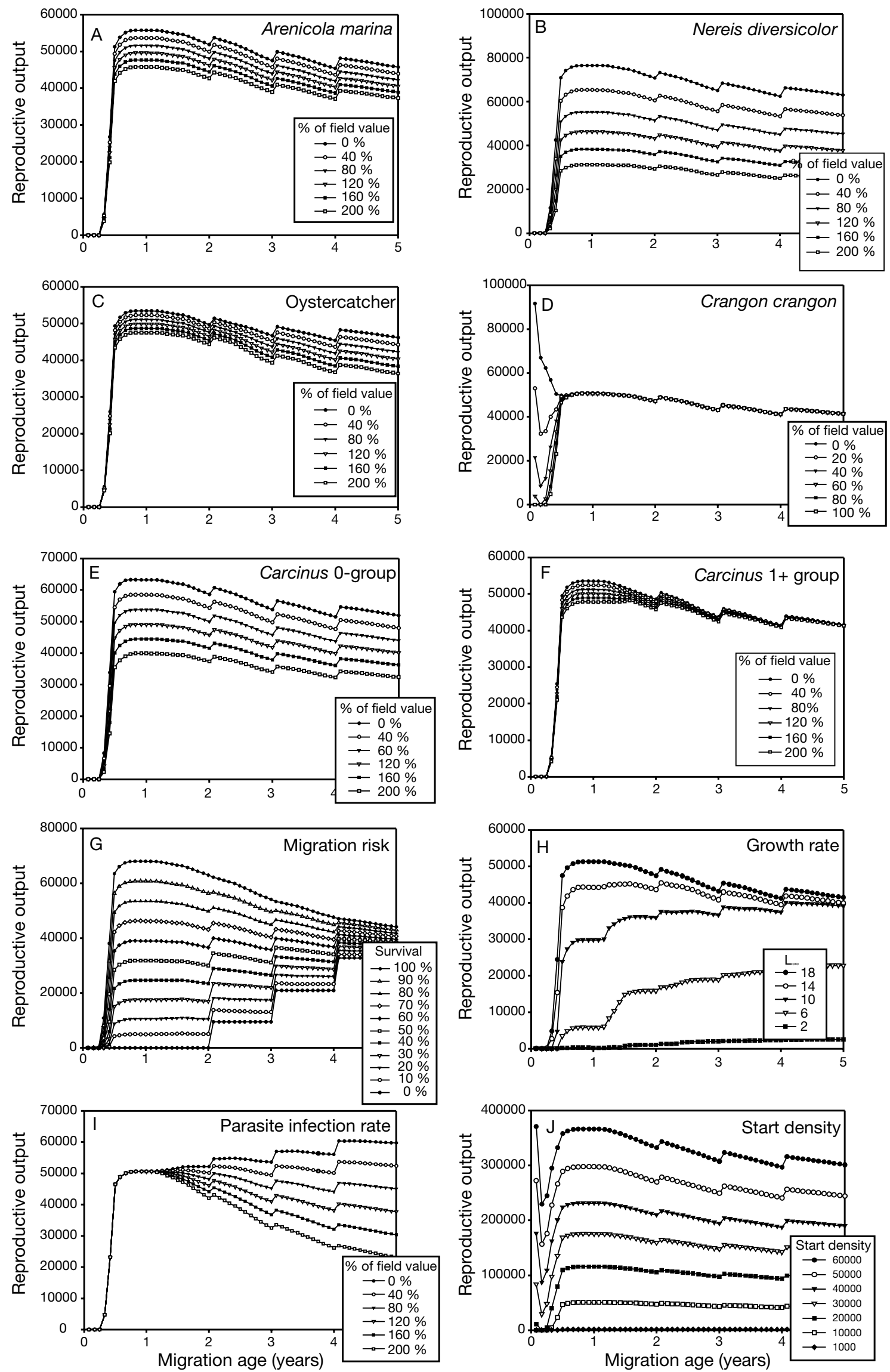
Fig. 5. Macoma balthica. Reproductive output over $5 \mathrm{yr}$ of a population (initial density $10000 \mathrm{~m}^{-2}$, except [J]), as a function of migration age (migration from high to low tidal flats), for different predation, parasite infection and migration mortality rates. All values are given as a percentage of estimated field value, except for migration survival (\% survival, field value $76 \%$ ) and growth rate, where the $\mathrm{L}_{\infty}$ is given (field value $17.5 \mathrm{~mm}$ ). The first and last point on the time axis represent 'always low' and 'always high' and therefore, no migration

\section{Nursery use and the best strategy}

The above sections analysed the effect of spring and winter migration date separately; here, the effect of both migrations on the RO are analysed together. The strategy that maximises RO of Macoma balthica is an immediate settlement at the high tidal flats and a migration back to the low tidal flats in January of their first winter (Fig. 7). The RO of bivalves that initially settle in the low intertidal $\left(54 \times 10^{3}\right)$, as was observed in the Wadden Sea (Hiddink \& Wolff 2002), is lower than that of those that initially settle in the high intertidal $\left(63 \times 10^{3}\right)$.

\section{DISCUSSION}

An important conclusion of this study is that the model cannot fully explain mortality as observed on the Groninger Wad. This can be due to an underestimation of the predation pressure of one or more of the included predators, or due to not including other important factors in the analysis. The underestimation of mortality can probably be explained from an underestimation of epibenthic predator densities, omission of

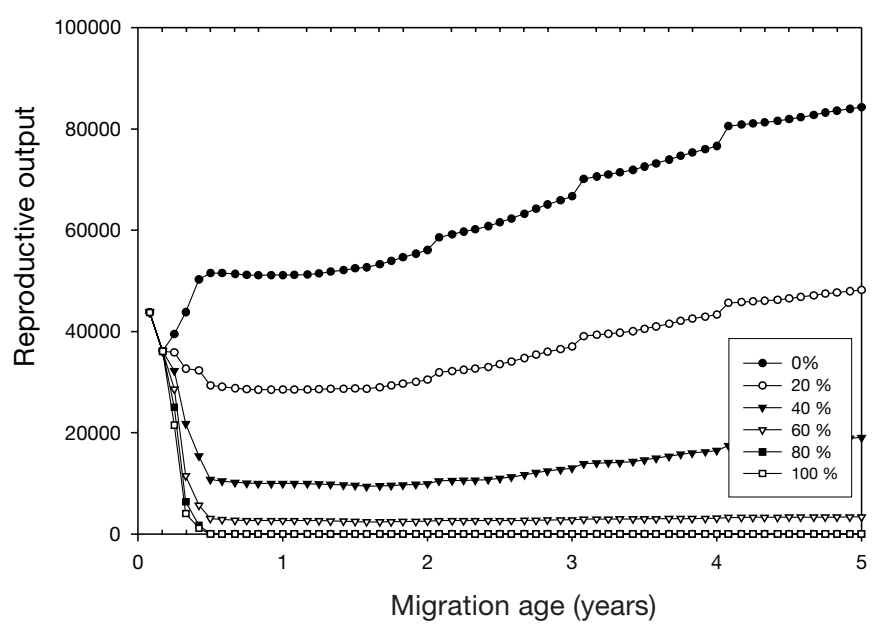

Fig. 6. Macoma balthica. Reproductive output as a function of migration age (migration from low to high tidal flats) in the model, for different values of Crangon crangon predation pressure (100\% is observed field density). The first and last point on the time axis represent 'always high' and 'always low' and therefore, no migration shelduck predation and other Macoma balthica eating waders from the model, or mortality caused by Parvatrema affinis and other parasites. Of these, shelduck predation and parasite-induced death are best established by studies. Shelducks eat M. balthica (Goethe 1961, Olney 1965, Poutsma 1969) and are common on the tidal flats of Groninger Wad from September to November (1000 to 7000 at high tide roosts; De Jong $\&$ Koks 1999). The shelduck was not included in the model because data on the functional response are not available. In the model calculations, it was assumed that no extra mortality was caused by the parasites. This assumption is probably not right because: (1) heavy infestation by trematode cercariae and metacercariae causes damage to host tissues (Lauckner 1983); and (2) P. affinis causes M. balthica to create crawling tracks (Swennen \& Ching 1974), which in turn may increase shorebird predation (but see Mouritsen 1997, Edelaar et al. 2002). This will have led to an underestimation of infection and mortality rates,

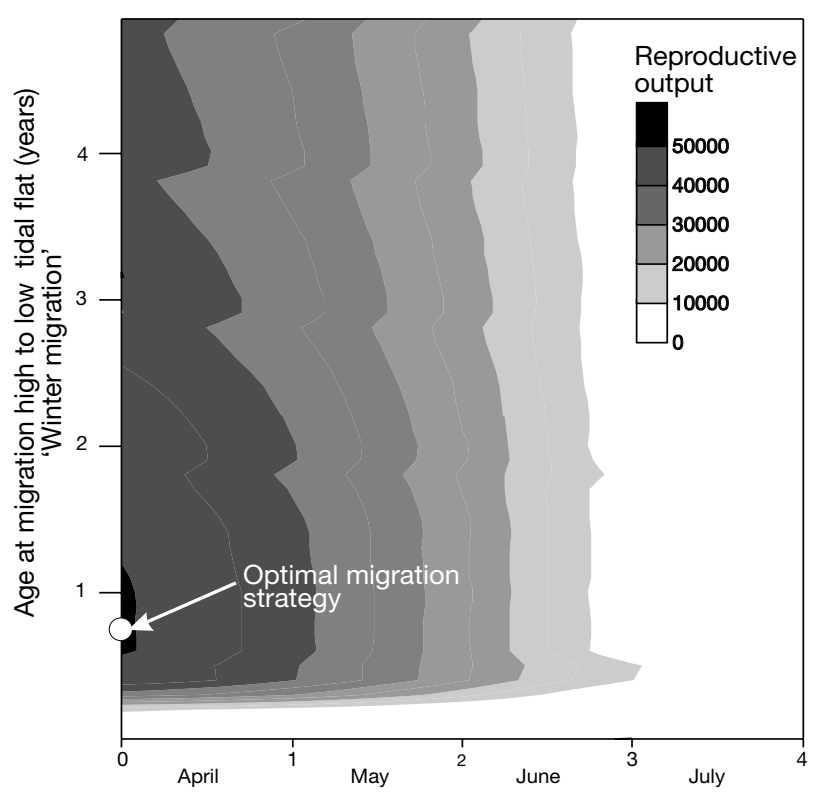

Age at migration low to high tidal flat (months) 'Spring migration'

Fig. 7. Macoma balthica. Contour plot of reproductive output (RO) as a function of spring and winter migration date. The highest RO is found after settlement in the high intertidal (age $=0 \mathrm{mo}$ ) and a subsequent migration to the low tidal flat in January of their first winter 
so the effect of $P$. affinis on $M$. balthica fitness will probably even be larger. The assumptions that juvenile $M$. balthica is not infected by $P$. affinis (or is it just not visible?) and that animals in the low intertidal zone are not infected were important in this study and should be studied further.

Since mortality of Macoma balthica at the Groninger Wad could not completely be explained, the model is useful for testing the hypotheses related to factors that have been included in the model only. It is difficult to say how including the additional mortality causing agents in the model would affect the conclusions of this study, because the direction of the effect heavily depends on the spatial distribution and size selection of the process, predator or parasite causing the mortality. If the underestimation of mortality is caused by an underestimation of the abundance and/or intake rates of all predators that were already included, the benefits of migration would increase. Nevertheless, tests with my current model led to acceptation or rejection of hypotheses as to why M. balthica migrates on the tidal flats of the Wadden Sea without explaining all mortality on the tidal flats. Future studies may elucidate what the other mortality causing factors and whether these factors affect the benefits of migrations for M. balthica.

The model calculations showed that the Beukema's (1993) hypothesis that migrations are an adaptation to avoid bird predation can be rejected because in the model, the presence or absence of oystercatchers did not have an effect on the profitability of migration. The hypotheses that nursery use and migrations are adaptive because they help to avoid epibenthic predation on juveniles and parasitation on the adults could not be rejected because both epibenthic predation by Crangon crangon and parasitation by Parvatrema affinis made it profitable to use nurseries for Macoma balthica at their natural densities. Therefore, it may be concluded that the spring and winter migrations of $M$. balthica serve as adaptations to avoid shrimp predation on spat and parasitation on large M. balthica. By leaving the low intertidal soon after settlement, $M$. balthica can increase the survival of small spat because shrimps are less abundant in the high intertidal. After $M$. balthica has outgrown the size range that is eaten by shrimps, it enters the size class that is vulnerable for infestation (and parasitic castration) by the parasitic trematode $P$. affinis, that is most common in the high intertidal. In the long run, the high mortality during the migration is outweighed by the increased $\mathrm{RO}$ of longer living, non-infested animals. Although other predators do affect the RO of $M$. balthica, they do not have an effect on which migration strategy yields the highest RO. The model shows that the spring migration will be beneficial even if the mortality caused by the spring migration is very high (less than $10 \%$ survival). The winter migration is only worthwhile when migration causes an additional mortality smaller than $30 \%$.

Thus, taking the risks of the migration increases fitness, because the migration risk is traded off against an increased RO. The cost is paid by the fraction of Macoma balthica that die/disappear during migration, while the survivors receive the benefits. Fig. 4 shows that the differences in RO between migrating and nonmigrating $M$. balthica only become apparent after 2 yr. It can therefore be predicted, also in accordance with life-history theory, that animals with a short lifeexpectancy (or with a higher predation risk during migration) should not migrate. This may explain the large remaining variation in the field, with some 0 -group living in the low intertidal and many adult $M$. balthica living on the high tidal flats. Nevertheless, if the fitness of the majority of $M$. balthica is increased by the migration, the evolution of migration behaviour may be expected.

The hypotheses of Beukema (1993) that nursery use of Macoma balthica and the associated migrations are an adaptation to avoid disturbance of the juveniles and to find the best growing conditions for both adults and juveniles were not tested in this study.

Beukema (1993) showed that after mild winters with many shrimps and poor Macoma balthica recruitment, 0-group M. balthica was concentrated in the high intertidal, while after cold winters with few shrimps, the majority of the abundant 0 -group lived around mean tidal level. This shows that in years with few shrimps, spat can live at lower tidal levels (Beukema et al. 1998) and the spring migration is less obligate. This illustrates the importance of shrimps for nursery use of $M$. balthica. The change in distribution from the low to the high intertidal zone in spring can at least partly be explained by a migration (Hiddink \& Wolff 2002), but the above observation suggests that it can also be explained by direct effects of shrimps on low tidal levels (either predation or induced migration due to the presence of shrimps). The migratory behaviour may also explain why $M$. balthica is one of the most common macrozoobenthic species of the Wadden Sea. The use of a shrimp refuge by juveniles effectively prevents the complete recruitment failure so frequently observed in certain years in other bivalve species in the Wadden Sea (Beukema 1993).

From experiments and observations in Hiddink et al. (2002b) and the (dependent) analysis in the current paper, a higher mortality of 0-group Macoma balthica in the low intertidal and a higher mortality of $1+$ group M. balthica in the high intertidal would be expected. In fact, this is the reason why migrations increase the RO of migrating $M$. balthica and therefore of vital importance for my conclusions. Beukema (1993) showed 
that mortality for $1+$ group $M$. balthica was higher in the high intertidal. For 0-group $M$. balthica, mortality of the 1998 year class on the Groninger Wad was not significantly different between the low and high tidal flats (comparison of regression lines, $p=0.83$, analysis of data from Hiddink \& Wolff, 2002); however, for the 1999 year class, it was $\left(\mathrm{p}=0.03\right.$; low tidal flats $0.035 \mathrm{~d}^{-1}$ $>$ high tidal flats $0.005 \mathrm{~d}^{-1}$, analysis of data from Hiddink et al. 2002b). Therefore, there also seems to be some empirical evidence for differential mortality between the low and high tidal flats for both 0 - and $1+$ group $M$. balthica.

The last section of 'Results' shows that the migration strategy as observed on the Groninger Wad (Hiddink \& Wolff 2002) and other parts of the Wadden Sea (Armonies \& Hellwig-Armonies 1992, Beukema 1993) (settlement low, spring migration to high tidal flat, winter migration to low tidal flats) resulted in a lower RO than primary settlement in the high intertidal (and therefore, without spring migration). Hence, the observed migration strategy may not maximise fitness. While primary settlement of Macoma balthica is found primarily in the low intertidal in the sheltered Wadden Sea (Günther 1991, Armonies 1996, Hiddink \& Wolff 2002), settlement was highest in the high intertidal in the highly dynamic Westerschelde estuary (Bouma et al. 2001). Bouma et al. (2001) explain this pattern by showing that the location of primary $M$. balthica settlement is governed by local hydrodynamic conditions, implying that this location is not 'chosen' by $M$. balthica. Therefore, initial settlement in the low intertidal cannot be part of an adaptive strategy. However, given initial settlement in the low intertidal, the spring migration increases reproductive output and, hence, is adaptive.

Other explanations for the observed distribution and migration patterns of Macoma balthica are possible, such as differences in growth between low and high tidal flats, density dependent growth and migration as a proximate reaction to adverse circumstances, like freezing or predator/parasite presence. As $M$. balthica winter migration is triggered by low water temperatures (Sörlin 1988, Hiddink \& Wolff 2002), it may be argued that downward migration serves as a mechanism to avoid low temperatures in winter instead as an adaptive strategy to avoid parasites, as temperatures are lower in the high intertidal in winter. However, as $M$. balthica appears not to be sensitive to the winter temperatures encountered in the Wadden Sea (Ibing \& Theede 1975, Bourget 1983, Günther \& Niesel 1999), avoiding low temperatures does not seem a probable reason for the winter migration of $M$. balthica in the Wadden Sea. An analysis of proximate reactions on adverse circumstances, like low temperatures, as the reason for migration would require a very different modelling approach. In the analysis, possible differ- ences in growth between the low and high tidal flats were ignored, including the possibility of density dependent growth (Olafsson 1986, Kamermans et al. 1992, Skilleter \& Peterson 1994, Vincent et al. 1994, Azouzi et al. 2002). Observations of density dependent growth of 0-group $M$. balthica on tidal flats have to be interpreted with care anyhow, as the combination of low densities and large $M$. balthica (and vice versa) may also be the result of a heavy selective predation of shrimps and other epibenthic predators on small $M$. balthica. Available evidence suggests that growth rates for older $M$. balthica are higher on low tidal flats, and higher for juveniles on high tidal flats (Armonies \& Hellwig-Armonies 1992, Beukema 1993), which would increase the benefits of the winter migration. However, without good information about growth rates of juveniles and adults on the low and high tidal flats as well as the density dependence of this growth, it is difficult to say something meaningful about the effect of density dependence on the adaptive value of migration.

This study tested the adaptive value of the differing distribution of Macoma balthica age groups on the tidal flats of the Wadden Sea, but $M$. balthica also occurs in the subtidal Wadden and North Sea. The absence of 0 -group $M$. balthica from the subtidal as well as the winter migration to the North Sea (Hiddink \& Wolff 2002) may be explained in the same way (migration mortality, shrimp predation, parasite infestation) as on tidal flats. Although the polychaete Nereis diversicolor, which eats much spat, is rare in the subtidal zone (Hiddink et al. 2002c), the predation pressure by shrimps is probably even higher than on the tidal flats because shrimps are larger and more abundant (Boddeke 1996, Hostens 2000). Thus, the subtidal zone is probably a hostile environment for small $M$. balthica, while the absence of $P$. affinis makes the subtidal zone attractive for adults. Therefore, on a larger scale, the same processes may be important for migration as on a tidal flat scale.

On an even larger scale, Macoma balthica also occurs in locations where no intertidal nurseries exist, e.g. in the Baltic Sea. Here, M. balthica does not undertake any migrations as the predator Crangon crangon is not present (Bonsdorff et al. 1993). Fig. 5J shows that only at very high settlement densities (>30000 $\mathrm{m}^{-2}$ ) will some $M$. balthica survive in the low intertidal (due to swamping of C. crangon) and that at densities $>60000 \mathrm{~m}^{-2}$, staying in the high intertidal does not increase fitness. Extremely high settlement densities of $300000 \mathrm{~m}^{-2}$ do occur in the subtidal Baltic Sea (Bonsdorff et al. 1993) and reasoning that the abundance of shrimps in the subtidal zone of the Baltic is not much higher than in the low intertidal zone of the Wadden Sea, may explain why some $M$. balthica survive in the Baltic without using intertidal refuges. 
Acknowledgements. A. G. Brinkman (Alterra) commented on the structure of the model. L. Zwarts (RIZA) and B. J. Ens (Alterra) provided information and data for constructing the functional response of Haematopus ostralegus foraging on Macoma balthica. Comments by W. J. Wolff (University of Groningen), J. J. Poos (RIVO) and the anonymous reviewers improved an earlier version of the manuscript.

\section{LITERATURE CITED}

Armonies W (1996) Changes in distribution patterns of 0-group bivalves in the Wadden Sea: Byssus-drifting releases juveniles from the constraints of hydrography. J Sea Res 35:323-334

Armonies W, Hellwig-Armonies M (1992) Passive settlement of Macoma balthica spat on tidal flats of the Wadden Sea and subsequent migration of juveniles. Neth J Sea Res 29: 371-378

Azouzi L, Bourget E, Borcard D (2002) Spatial variation of the intertidal bivalve Macoma balthica: biotic variables in relation to density and abiotic factors. Mar Ecol Prog Ser 234:159-170

Beukema JJ (1993) Successive changes in distribution patterns as an adaptive strategy in the bivalve Macoma balthica (L.) in the Wadden Sea. Helgol Meeresunters 47: 287-304

Beukema JJ, De Vlas J (1989) Tidal-current transport of thread-drifting postlarval juveniles of the bivalve Macoma balthica from the Wadden Sea (Netherlands) to the North Sea. Mar Ecol Prog Ser 52:193-200

Beukema JJ, Meehan BW (1985) Latitudinal variation in linear growth and other shell characteristics of Macoma balthica. Mar Biol 90:27-33

Beukema JJ, Honkoop PJC, Dekker R (1998) Recruitment in Macoma balthica after mild and cold winters and its possible control by egg production and shrimp predation. Hydrobiologia 375/376:23-34

Beukema JJ, Drent J, Honkoop PJC (2001) Maximizing lifetime egg production in a Wadden Sea population of the tellinid bivalve Macoma balthica: a trade-off between immediate and future reproductive outputs. Mar Ecol Prog Ser 209:119-129

Boddeke R (1996) Changes in the brown shrimp (Crangon crangon L.) population off the Dutch coast in relation to fisheries and phosphate discharge. ICES J Mar Sci 53: 995-1002

Bonsdorff E, Norkko A, Boström C (1993) Recruitment and population maintenance of the bivalve Macoma balthica (L.). Factors affecting settling success and early survival on shallow sandy bottoms. In: Eleftheriou A, Ansell AD, Smith CJ (eds) Biology and ecology of shallow coastal waters. Olsen \& Olsen, Fredensborg

Bouma H, Duiker JMC, De Vries PP, Herman PMJ, Wolff WJ (2001) Spatial pattern of early recruitment of Macoma balthica (L.) and Cerastoderma edule (L.) in relation to sediment dynamics on a highly dynamic intertidal sandflat. J Sea Res 45:79-93

Bourget E (1983) Seasonal variations of cold tolerance in intertidal molluscs and relation to environmental conditions in the St. Lawrence estuary. Can J Zool 61: 1193-1201

Bunskoeke EJ, Ens BJ, Hulscher JB, De Vlas SJ (1996) Why do oystercatchers Haematopus ostralegus switch from feeding on Baltic tellin Macoma balthica to feeding on the ragworm Nereis diversicolor during the breeding season? Ardea 84A:91-104
De Jong J, Koks B (1999) Wadvogels in de westelijke Noordpolder. Grauwe gors 27:117-134

Edelaar P, Drent J, De Goeij P (2002) A double test of the parasite manipulation hypothesis in a burrowing bivalve. Oecologia 134:66-71

Goethe F (1961) The moult gatherings and moult migration of the Shelduck in north-west Germany. Br Birds 54:145-161

Günther CP (1991) Settlement of Macoma balthica on an intertidal sandflat in the Wadden Sea. Mar Ecol Prog Ser 76:73-79

Günther CP, Niesel V (1999) Effects of the ice winter 1995/96. In: Dittman S (ed) The Wadden Sea ecosystem. Stability properties and mechanisms. Springer-Verlag, Berlin, p 193-205

Hiddink JG, Wolff WJ (2002) Changes in distribution and decrease in numbers during migration of the bivalve Macoma balthica. Mar Ecol Prog Ser 233:117-130

Hiddink JG, Kock RP, Wolff WJ (2002a) Active pelagic migrations of the bivalve Macoma balthica are dangerous. Mar Biol 140:1149-1156

Hiddink JG, Marijnissen SAE, Troost K, Wolff WJ (2002b) Predation on the 0-group and older year classes of the bivalve Macoma balthica: interaction of size selection and intertidal distribution of epibenthic predators. J Exp Mar Biol Ecol 269:223-248

Hiddink JG, Ter Hofstede R, Wolff WJ (2002c) Predation of intertidal infauna on juveniles of the bivalve Macoma balthica. J Sea Res 47:139-157

Holling CS (1965) The functional response of predators to prey density and its role in mimicry and population regulation. Mem Entomol Soc Can 45:1-60

Hostens K (2000) Spatial patterns and seasonality in the epibenthic communities of the Westerschelde (Southern Bight of the North Sea). J Mar Biol Assoc UK 80:27-36

Hulscher JB (1973) Burying-depth and trematode infection in Macoma balthica. Neth J Sea Res 6:141-156

Hulscher JB (1982) The oystercatcher Haematopus ostralegus as a predator of the bivalve Macoma balthica in the Dutch Wadden Sea. Ardea 70:89-152

Ibing J, Theede H (1975) Zur Gefrierresistenz littoraler Mollusken von der deutschen Nordseeküste. Kiel Meeresforsch 31:44-49

Kamermans P, Van der Veer HW, Karczmarski L, Doeglas GW (1992) Competition in deposit- and suspension-feeding bivalves: experiments in controlled outdoor environments. J Exp Mar Biol Ecol 162:113-135

King M (1995) Fisheries biology, assessment and management. Fishing News Books, Oxford

Klein Breteler WCM (1976) Settlement, growth and production of the shore crab Carcinus maenas on tidal flats of the Dutch Wadden Sea. Neth J Sea Res 10:354-376

Lauckner G (1983) Diseases of Mollusca: Bivalvia. In: Kinne O (ed) Diseases of marine animals. Vol II: Introduction, Bivalvia to Scaphopoda. Biologische Anstalt Helgoland, Hamburg, p 632-761

Lim SSL, Green RH (1991) The relationship between parasite load, crawling behaviour, and growth rate of Macoma balthica (L.) (Mollusca, Pelecypoda) from Hudson Bay, Canada. Can J Zool 69:2202-2208

Mouritsen KN (1997) Crawling behaviour in the bivalve Macoma balthica: the parasite-manipulation hypothesis revisited. Oikos 79:513-520

Olafsson EB (1986) Density dependence in suspension-feeding and deposit-feeding populations of the bivalve Macoma balthica: a field experiment. J Anim Ecol 55:517-526

Olney PJS (1965) Food and feeding habits of the shelduck Tadorna tadorna. Ibis 107:527-532 
Pekkarinen M (1987) Notes on a gymnophallid trematode assumed to be Parvatrema affinis (Jameson \& Nicoll, 1913), from Macoma balthica. Ann Zool Fenn 24:29-37

Poutsma J (1969) Oriënterend onderzoek naar het menu van de Bergeend (Tadorna tadorna (Linnaeus) en de Bonte strandloper (Calidris alpina) (Linneaus)) op het Groninger Wad. M.O.-onderwerp-Zoologische Oecologie. Zoologisch laboratorium, Baflo, p 1-38

Sigurdsson JB, Titman CW, Davis PA (1976) The dispersal of young post-larval bivalve molluscs by byssus threads. Nature 262:386-387

Skilleter GA, Peterson CH (1994) Control of foraging behavior of individuals within an ecosystem context: the clam Macoma balthica and interactions between competition and siphon cropping. Oecologia 100:268-278

Sörlin T (1988) Floating behaviour in the tellinid bivalve Macoma balthica (L.). Oecologia 77:273-277

Swennen C, Ching HL (1974) Observation on the trematode Parvatrema affinis, causative agent of crawling tracks of Macoma balthica. Neth J Sea Res 8:108-115

Van der Meer J, Beukema JJ, Dekker R (2001) Long-term variability in secondary production of an intertidal bivalve

Editorial responsibility: Otto Kinne (Editor),

Oldendorf/Luhe, Germany population is primarily a matter of recruitment variability. J Anim Ecol 70:159-169

Vincent B, Joly D, Harvey M (1994) Spatial variation in growth of the bivalve Macoma balthica (L.) on a tidal flat: Effects of environmental factors and intraspecific competition. J Exp Mar Biol Ecol 181:223-238

Wennhage H, Pihl L (2001) Settlement patterns of newly settled plaice (Pleuronectes platessa) in a non-tidal Swedish fjord in relation to larval supply and benthic predators. Mar Biol 139:877-889

Werner EE, Gilliam JF (1984) The ontogenetic niche and species interactions in size-structured populations. Annu Rev Ecol Syst 15:393-425

Wolff WJ, Van Haperen AMM, Sandee AJJ, Baptist HJM, Saeijs HLF (1975) The trophic role of birds in the Grevelingen estuary, The Netherlands, as compared to their role in the saline lake Grevelingen. In: Persoone G, Jaspers E (eds) Proc 10th Eur Mar Biol Symp, Vol 2. Universa Press, Wetteren, p 673-689

Yates MG, Goss-Custard JD (1991) A comparison between high water and low water counts of shorebirds on the Wash, east England. Bird Study 38:179-187

Submitted: September 19, 2002; Accepted: December 17, 2002 Proofs received from author(s): April 7, 2003 